\title{
The oxidation - reduction characteristics of Ngoc Tu granitoid block and their specialized chemistry of geochemistry
}

\author{
Nguyen Duc Do ${ }^{1,}{ }^{*}$, Niem Van Nguyen ${ }^{1}$, Thanh Hung Pham ${ }^{1}$, Hieu Cong Duong ${ }^{1}$, \\ Tan Trong Bui ${ }^{1}$, Linh Thuy Thi Hoang ${ }^{1}$, Tien Cong Dinh ${ }^{1}$, Thoa Thi Hoang ${ }^{2}$ \\ ${ }^{1}$ Vietnam Institute of Sciences and Mineral Resources, Hanoi, Vienam \\ ${ }^{2}$ Hanoi University of Mining and Geology, Hanoi, Vietnam
}

\begin{abstract}
ARTICLE INFO
ABSTRACT

Article history:

Received $16^{\text {th }}$ Oct. 2020

Revised 03 ${ }^{\text {rd Jan. } 2021}$

Accepted 02 ${ }^{\text {nd }}$ Feb. 2021

Keywords:

Ngoc Tu granitoid block, Oxidation-reduction, Specialized chemistry of geochemistry.

Oxidation-reductionstate of magma in general and granitoid in particular is important for determining themetallogenetic potential of magma bodies. Redox conditions help to interpret the specialized chemistry of geochemistry not only at the content level, but also on the geochemical behavior of the elements. The research on primary inclusions of magma by hermobarogeochemical method of RAMAN equipment has identified that Ngoc Tu granitoid block is in the oxidized state indicated by $\mathrm{CO}_{2}$-rich primary inclusions. This condition shows that the $\mathrm{Ngoc} \mathrm{Tu}$ granitoidblock is not favorable for the metalogical potential of Sn, but it can be advantageous for the movements of Mo, $W$ from magmatic solution into ore solution.
\end{abstract}

Copyright (C) 2021 Hanoi University of Mining and Geology. All rights reserved.

${ }^{*}$ Corresponding author

E - mail: nguyen180@gmail.com

DOI: 10.46326/JMES.2021.62(1).07 


\title{
Đặc tính môi trường oxy hóa - khử của granitoid khối Ngọc Tụ và tính chuyên hóa địa hóa của chúng
}

\author{
Đỗ Đức Nguyên ${ }^{1}{ }^{*}$, Nguyễn Văn Niệm ${ }^{1}$, Phạm Hùng Thanh ${ }^{1}$, Dương Công Hiếu ${ }^{1}$, \\ Bui Trọng Tấn ${ }^{1}$, Hoang Thị Thuy Linh ${ }^{1}$, Đinh Công Tiến ${ }^{1}$, Hoang Thị Thoa ${ }^{2}$ \\ 1 Viện Khoa học Địa chất và Khoáng sản, Hà Nội, Việt Nam \\ 2 Trường Đại học Mỏ - Địa chất, Hà Nội, Việt Nam
}

\begin{abstract}
THÔNG TIN BÀI BÁO
Quá trình:

Nhận bài 16/10/2020

Sửa xong 03/01/2021

Chấp nhận đăng 02/02/2021

Tù khóa:

Chuyên hóa địa hóa,

Granitoid khối Ngọc Tụ,

Oxy hóa-khử.

\section{TÓM TẮT}

Trạng thái oxy hóa - khư của magma nói chung và granitoid nói riêng có ý nghĩa quan trọng khi xác định tiềm năng sinh khoáng của thể magma. Điều kiện oxy hóa - khử giúp cho việc luận giải tính chuyên hóa địa hóa không chỉ theo mức hàm lượng mà dựa cả vào hành vi địa hóa của nguyên tố. Việc nghiên cúu bao thể nguyên sinh của magma bằng phương pháp địa hóa nhiệt áp trên thiết bi RAMAN đã xác định granitoid khối Ngọc Tu mang đặc tính oxy hóa được chỉ thị bởi các bao thể nguyên sinh giàu CO $\mathrm{O}_{2}$. Điều kiền này cho thấy granitoid khối Ngọc Tụ không thuận lợi cho tính chuyên hóa sinh khoáng của Sn nhưng có thể thuận lợi cho việc di chuyển Mo, W tù̀ dung thể magma vào dung dịch quặng.
\end{abstract}

(C) 2021 Trường Đại học Mỏ - Địa chất. Tất cả các quyền được bảo đảm.

\section{Mở đầu}

Granitoid khối Ngọc Tụ nói riêng được nhiều công trình nghiên cứu và có quan niệm liên quan đến tiềm năng khoáng hóa thiếc $(\mathrm{Sn})$, wolfram (W). Tuy nhiên, chưa có công trình nào khẳng định rõ ràng về khả năng sinh khoáng Sn ở khối Ngọc Tụ, mặc dù Dương Đức Kiêm (2006) phát hiện biểu hiện khoáng hóa Sn. Kết quả này dựa theo các tham số địa hóa đới biểu sinh với tài liệu địa hóa đá gốc sử dụng các phương pháp bán định lượng nên không có ý nghĩa xác định tính chuyên hóa của

\section{*Tác giả liên hệ}

E - mail: nguyen180@gmail.com

DOI: 10.46326/JMES.2021.62(1).07 magma. Đồng thời, chưa chi tiết hóađược các kiểu biến đổi liên quan với khoáng hóa.

Trong khi đó, tính chuyên hóa địa hóa của molypden (Mo) chưa được xác định; còn $\mathrm{Sn}, \mathrm{W}, \mathrm{Cu}$ được xác định bằng phương pháp bán định lượng. Đặc biệt, trạng thái oxy hóa - khử của granitoid không được nghiên cứu. Đây là điều kiện quyết định đến hành vi địa hóa của $\mathrm{Sn}, \mathrm{Mo}, \mathrm{W}, \mathrm{Cu}, . .$. có khả năng di chuyển từ dung thể magma khi kết tinh để đi vào dung thể tạo quặng hay không.

Để làm rõ vấn để này, tập thể tác giả khảo sát và lấy mẫu (Hình 2) nghiên cứu hệ thống từ rìa tới trung tâm khối, các tướng của granitoid, đới biến đổi, cấu trúc địa chất liên quan. Từ đó xây dựng cơ sở dữ liệu định lượng gồm: 1) Phân tích 24 mẫu lát mỏng đá granitoid (12 mẫu đá granitoid porphyr 6 mẫu đá granitoid hạt nhỏ, 13 mẫu đá 
granitoid bị biến đổi); 2) Phân tích 21 mẫu địa hóa các nguyên tố hiếm vết; 3) Phân tích thành phần bao thể nguyên sinh trong đá tổng.

\section{2. Đặc điểm địa chất khối Ngọc Tụ}

Khối granitoid Ngọc Tụ (Hình 1) là một trong những đỉnh núi cao nhất trong vùng, cách huyện Đăk Tô, tỉnh Kon Tum khoảng 16 km về phía tây bắc. Trước đây Trần Tính, Nguyễn Văn Trang, (1994), Nguyễn Quang Lộc (1998) đã xác lập và xếp vào phức hệ Bà Nà với tuổi $K_{2}$. Khối Ngọc Tụ có hình dạng khá đẳng thước, diện tích khoảng 120 km². Khối granitoid này xuyên cắt qua gneis biotit, plagiocla hệ tầng Tắc Pỏ và granit biotit của phức hệ Hải Vân. Ở rìa tiếp xúc phổ biến hiện tượng albit hoá và các đá sừng: đá sừng thạch anh - felspat - mica, sừng thạch anh - biotit - cordierit. Thành phần thạch học của khối gồm granitoid sáng màu nhưng có nhiều tướng khác nhau và ranh giới không rõ ràng, gồm: các kiểu granitoid porphyr đến hạt vừa, granitoid hạt nhỏ. Ngoài ra, còn pha đá mạch trong nội khối magma.

- Pha 1có kiểu đá granitoidporphyr vừa, tương đối sáng màu, cấu tạo khối. Thành phần chủ yếu gồm felspat, thạch anh, muscovit, biotit.

Thành phần khoáng vật: các khoáng vật chủ yếu là plagiocla $(40 \div 42 \%)$, felspat kali (orthoclas + microclin): $32 \div 34 \%$, thach anh $23 \div 25 \%$, biotit: $2 \%$, muscovit $1 \div 2 \%$. Biotit thường bị chlorit hóa.

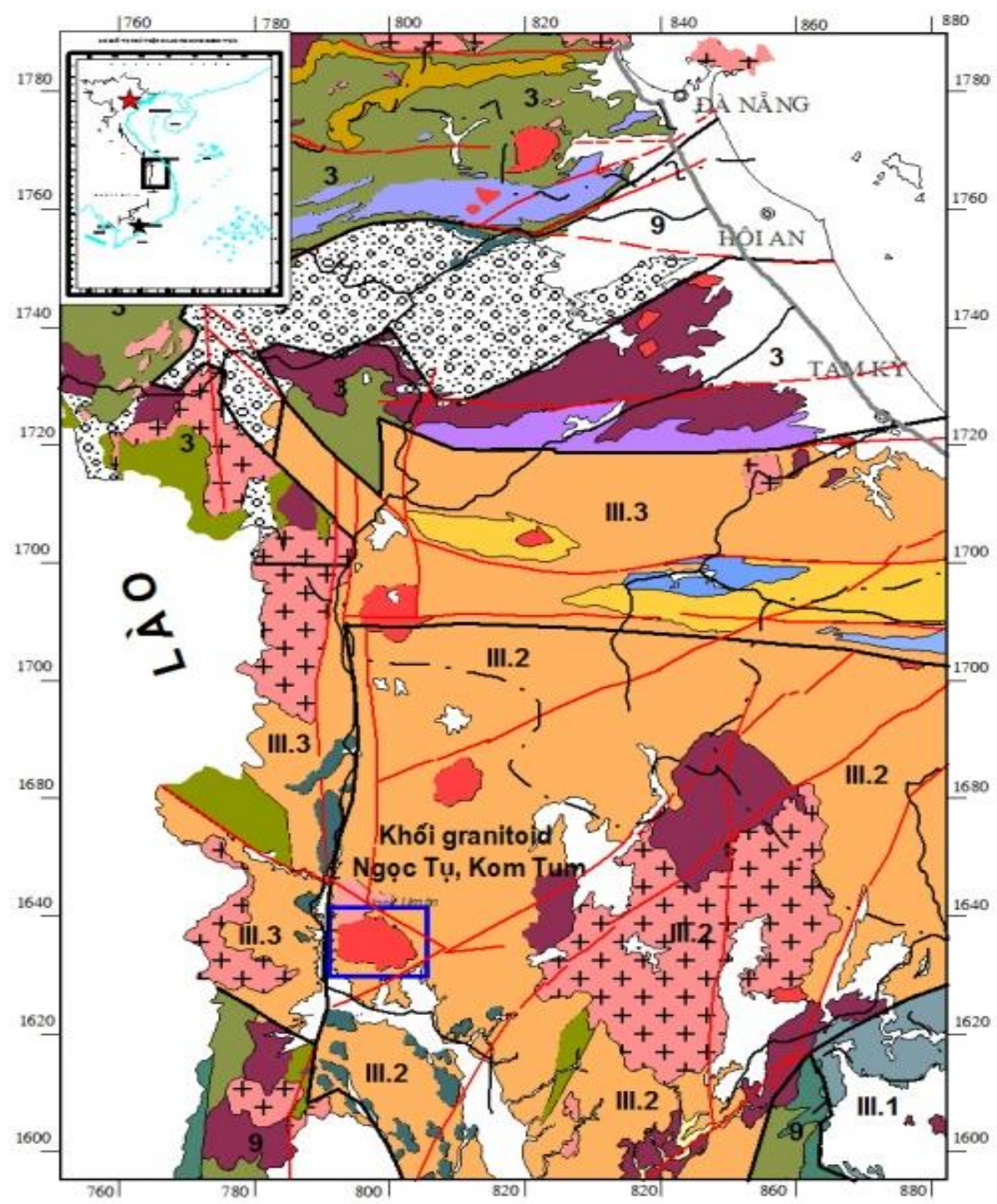

Hình 1. Sơ đồ vị trí khối granioid Ngọc Tụ trong khu vực Tây Nguyên. 


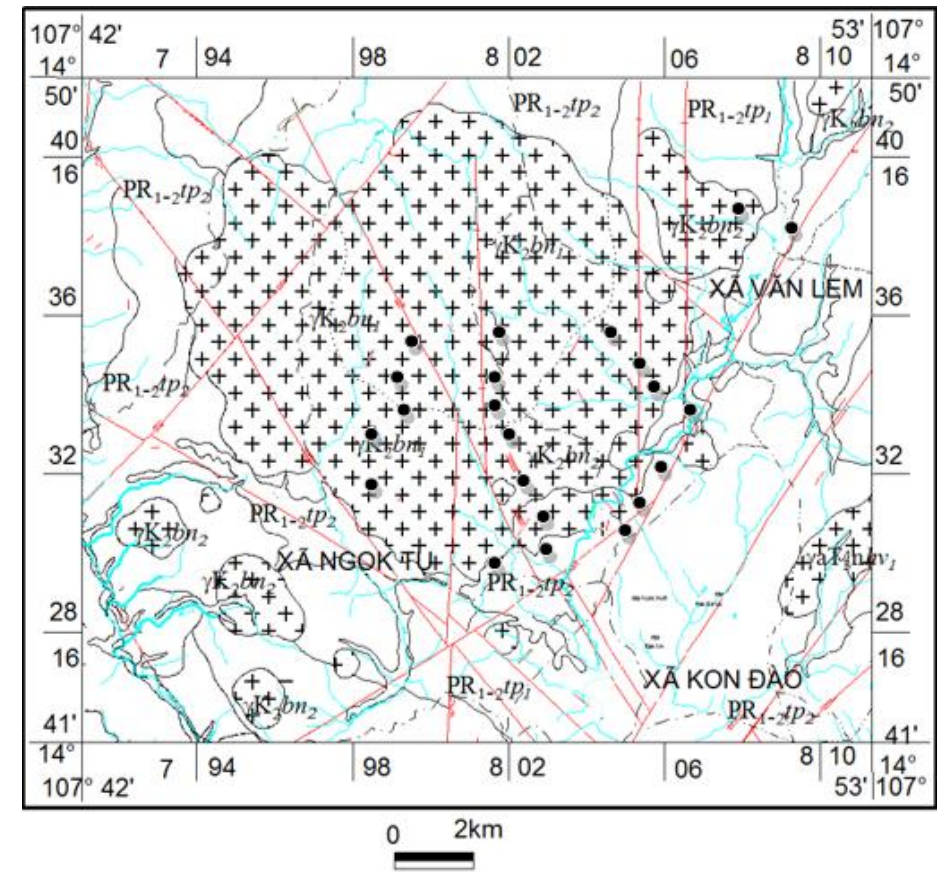

Hình 2. Sơ đồ vị trí lấy mẫu khối granioid Ngọc Tụ (• Điểm lấy mẫu).

- Pha 2 có kiểu đá granitoid hạt nhỏ đến vừa, tương đối sẫm màu, cấu tạo khối. Thành phần chủ yếu gồm felspat, thạch anh, muscovit, biotit.

Thành phần khoáng vật: các khoáng vật chủ yếu là plagiocla $(20 \div 31 \%)$, felspat kali (orthoclas + microclin): $34 \div 49 \%$, thach anh $26 \div 30 \%$, biotit: $1 \div 2 \%$, muscovit $1 \div 2 \%$. Biotit thường bị chlorit hóa.

Đới biến đổi berezit hóa có đặc điểm như sau:

- Phần đá gốc tàn dư là felspat kali $(52 \div 53 \%)$ dạng tấm lớn, phân bố rất không đều, bề mặt mờ đục, dọc theo cát khai của felspat kali phát triển dày đặc sericit dạng vảy.

- Phần nhiệt dịch: phân bố rất không đều; thành phần là thạch anh $(35 \div 37 \%)$ dạng hạt lớn méo mó, muscovit $(3 \div 4 \%)$ dạng tấm, dạng méo mó, không màu, giao thoa cao; sericit $(7 \div 9 \%)$ dạng vảy, bề mặt sạch, thường tạo đám - ổ không đều.

Tuổi thành tạo zircon trong granitoid được xác định bằng phương pháp $\mathrm{U}-\mathrm{Pb}$, zircon, SHRIMP tại Viện Địa chất Liên bang Nga mang tên A.P. Kapinski (VSEGEI) là 244,5 $\pm 1,5$ Tr.n $\left(T_{2}\right)$ (Nguyễn Văn Niệm, Đỗ Đức Nguyên, 2018). Kết quả này tương đồng với xác định tuổi đồng vị bằng phương pháp $\mathrm{U}-\mathrm{Pb}$ đối với granit kiểu Bà Nà ở khối Ngọc Tụ cho tuổi $239 \div 240$ triệu năm tương ưng $T_{2}$ (Trần Hoàng Vũ, 2015).
Hệ thống các đứt gãy kiến tạo phương tây bắc đông nam chia cắt khá mạnh, tạo các đới khe nứt, dập vỡ mạnh thuận lợi cho các quá trình nhiệt dịch sau này.

\section{Phương pháp nghiên cứu}

Với mục tiêu làm rõ được vai trò sinh khoáng của thành tạo granitoid khối Ngọc Tụ, nhóm tác giả đã thu thập mẫu cho từng loại đá, đới biến đổi và đới biểu hiện khoáng hóa bao gồm mẫu lát mỏng thạch học, mẫu địa hóa đá gốc và đới biến đổi, mẫu nghiên cứu thành phần bao thể magma nguyên sinh.

Mẫu địa hóa nhóm nguyên tố vết được phân tích bằng phương pháp ICP - MS tại Viện Địa chất Viễn Đông - FEGI, LB Nga theo hệ thống từ rìa khối vào trung tâm, đặc trưng cho các kiểu đá gồm: granitoid giàu ổ pegmatit, granitoid hạt vừa, granitoid hạt nhỏ, đới biến đổi, đới dập vỡ kiến tạo, đới chứa sulfua. Tập mẫu này phục vụ nghiên cứu tính chuyên hóa địa hóa, xác định dị thường tối thiểu và giá trị đột biến góp phần tìm kiếm khoáng sản.

Mẫu bao thể nguyên sinh trong magma được thực hiện theo các bước: nghiên cứu và lấy mẫu đảm bảo tính đại diện của mẫu cho từng kiểu đá. Gia công và phân tích hai loại đá gồm: đá granitoid biotit hạt nhỏ và hạt vừa, chúng có ranh giới 
chuyển tiếp; đá biotit hạt nhỏ ở đới dập vỡ kiến tạo. Mẫu được gia công đến độ dày khoảng $1,0 \div 1,3$ mm, đánh bóng; kích thước 2,5x4,5 cm. Các mẫu được gia công và phân tích mẫu trên thiết bị Raman tại Phòng thí nghiệm Raman Viện Địa chất Viễn Đông, LB Nga. Bao thể nguyên sinh đặc trưng bởi một số đặc tính sau: nằm trong các tinh thể và là một phần liên kết ngẫu nhiên, có thể quan sát thấy dấu hiệu hướng phát triển của tinh thể nếu bao thể đạt kích thước đủ lớn (>1/10 lần tinh thể chứa chúng) hoặc dạng phát triển theo 3 phương (đây là dấu hiệu rất tin cậy); nó có thể nằm ở trung tâm, rìa hay vị trí tinh thể bị rửa lũa; trong một tinh thể chỉ chứa 1 bao thể; bao thể nguyên sinh thường có các bao không đều đặn, kích thước nhỏ (thứ sinh hoặc bao thể kết hợp) sắp xếp xung quanh hoặc đối diện nó.

Quy trình phân tích khái quát như sau: soi kính và tìm kiếm bao thể nguyên sinh, lựa chọn bao thể có kích thước phù hợp (>1 ppm, tối ưu từ 10 ppm trở lên), đánh dấu vị trí trên lát mỏng, vẽ sơ bộ hình dạng - đặc điểm của bao thể; chuyển sang thiết bị Raman, chuẩn thiết bị bằng mẫu $C$, đưa mẫu lát mỏng đã đánh dấu bao thể vào vị trí phân tích, chọn đầy đủ các bước sóng để quét tổng thể, tách từng bước sóng theo thành phần phân tích, ghi và lưu dữ liệu, chuyển vào hệ thống máy chủ để sử lý kết quả. Phương pháp này giúp nghiên cứu thành phần bao thể nguyên sinh (Primary inclusion) trong đá tổng, luận giải trạng thái oxy hóa - khử của granitoid một cách chính xác nhất, đánh giá khả năng sinh kim của granitoid.

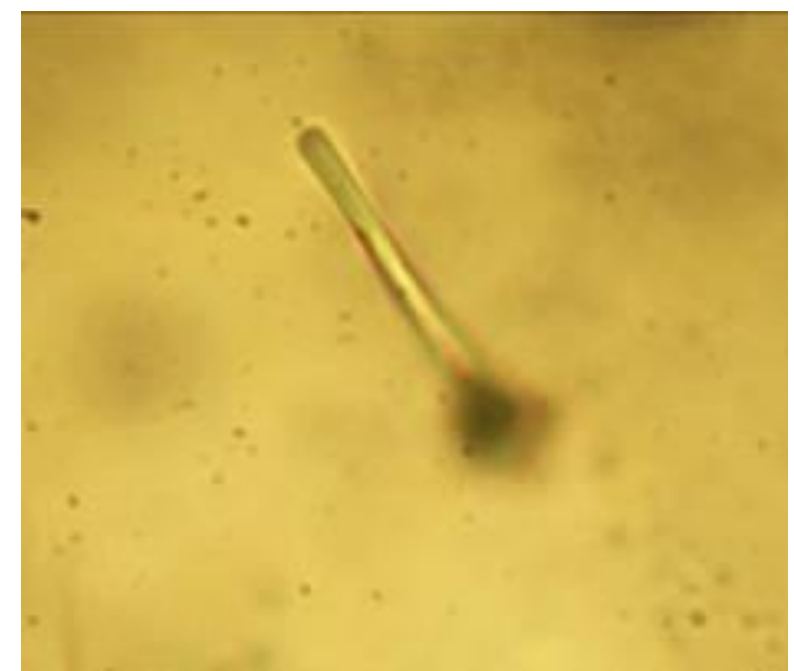

Tuy nhiên, loại đá hạt nhỏ chưa thể phát hiện được bao thể nguyên sinh bởi xác suất phát hiện được bao thể này trong đá rất thấp (khoảng 10\%) và kích thước của chúng nhỏ $(<1 \mathrm{ppm})$. Chỉ các bao thể nguyên sinh trong đá được sử dụng để nghiên cứu trạng thái oxy hóa - khử của magma.

Bên cạnh đó, tập thể tác giả cũng thu thập, nghiên cứu, sử dụng thành phần chính và vết của đá để tính toán điều kiện oxy hóa - khử. Từ đó, so sánh với phương pháp nghiên cứu bao thể nguyên sinh.

\section{Kết quả nghiên cứu và thảo luận}

\subsection{Kết quả phân tích bao thể}

Chỉ có 2 bao thể nguyên sinh được tìm thấy trong mẫu granitoid biotit hạt vừa, chúng nằm trong tinh thể thạch anh. Kích thước hai bao thể này là 10 và $15 \mathrm{ppm}$, xung quanh có các bao thể nhỏ thứ sinh, phân bố không đều (Hình 3).

Kết quả phân tích chỉ phát hiện được thành phần $\mathrm{CO}_{2}$ với mật độ cao $\left(0,55 \div 0,70 \mathrm{~g} / \mathrm{cm}^{3}\right)$, còn các thành phần khác không phát hiện được $\mathrm{CH}_{4}$, $\mathrm{H}_{2} \mathrm{~S}, \mathrm{SO}_{2}, \mathrm{H}_{2} \mathrm{O}, \mathrm{CO}, \mathrm{NH}_{3}$. Thành phần bao thể ở đây chỉ thị cho tính oxy hóa (Hình 4,5 ).

\subsection{Trạng thái oxy hóa của granitoid khối Ngọc Tu}

Granitoidporphyr sáng màu chiếm diện tích chủ yếu khối Ngọc Tụ, kết quả phân tích cho thấy các bao thể trong tinh thể thạch anh tìm thấy $\mathrm{CO}_{2}$ (Hình 3) đặc trưng cho môi trường magma nguyên sinh có tính oxy hóa.

Hình 3. Các bao thể nguyên sinh chứa $\mathrm{CO}_{2}$ trong khoáng vật thạch anh của đá granit biotit sáng màu, khối Ngoc Tu (50x). 

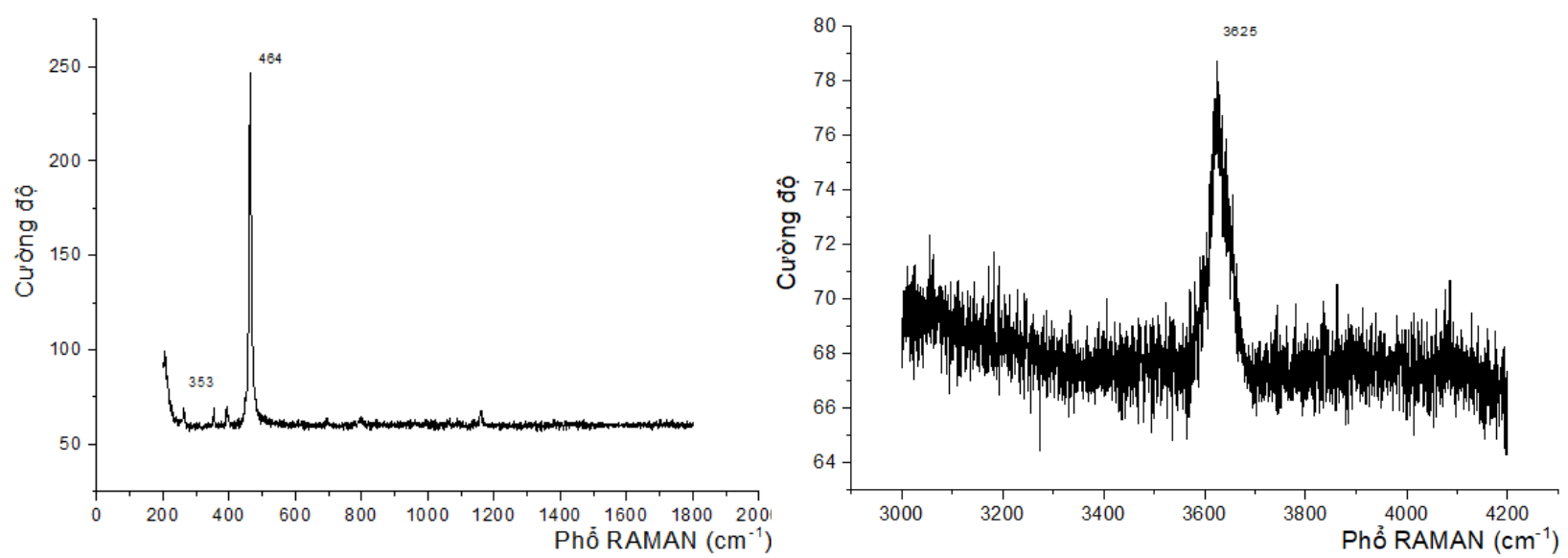

Hình 4. Phổ Raman xác định thành phần bao thể nguyên sinh và khoáng vật thạch anh của đá granit biotit sẫm màu gần ranh giới tiếp xúc với đá biến chất: Dải phổ của thạch anh 353, 393, 464 cm-1 ; của $\mathrm{H}_{2} \mathrm{O}$ là $3625 \mathrm{~cm}^{-1}$.
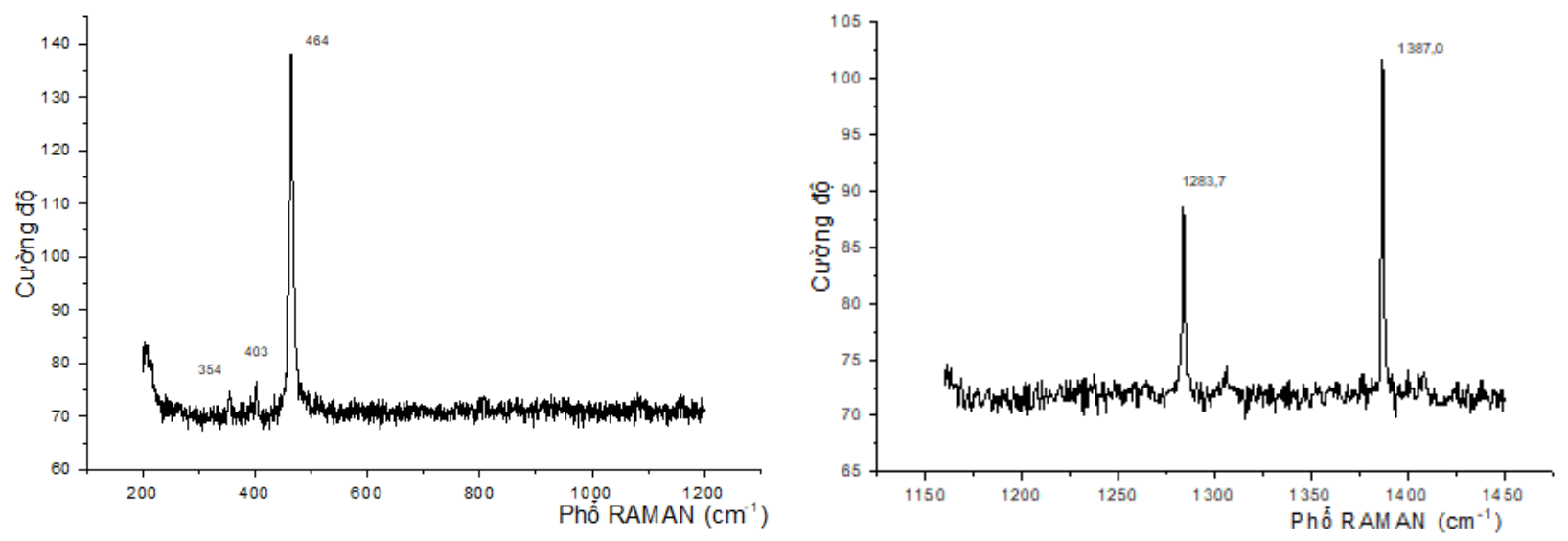

Hình 5. Phổ Raman xác định thành phần bao thểnguyên sinh và khoáng vật thạch anh của đá granit dạng porphyr sáng màu gần ranh giới tiếp xúc với đá biến chất: Dải phổ của thạch anh 3354, 403, 464 $\mathrm{cm}^{-1}$; của $\mathrm{CO}_{2} 1283,7 \div 1387,0 \mathrm{~cm}^{-1}$.

Trạng thái oxy hóa - khử còn thể hiện bằng các thành phần chính $(F e)$ và vết. Tuy nhiên, các yếu tố này rất dễ bi tác động bởi quá trình biến đổi thứ sinh. Ở đây, granitoid sáng màu tỷ lệ $\mathrm{Fe}_{2} \mathrm{O}_{3} / \mathrm{FeO}>$ 0,5 đặc trưng cho granitoid oxy hóa và ngược lại, granitoid sáng màu tỷ lệ $\mathrm{Fe}_{2} \mathrm{O}_{3} / \mathrm{FeO}<0,5$ đặc trưng cho granitoid khử. Đối với Ngọc Tụ, theo đặc điểm phân bố và tương quan giữa $\mathrm{Fe}^{2+}$ và $\mathrm{Fe}^{3+}$ (Nguyễn Quang Lộc, 1998) cho thấy dung thể magma granitoid thể hiện tính oxy hóa vừa đến mạnh (Hình 7), có khả năng thuân lợi sinh $W, W$ $M o$ (Hình 6). Tuy nhiên, việc sử dụng $\mathrm{Fe}^{2+}$ và $\mathrm{Fe}^{3+}$ để phân chia môi trường địa hóa của magma granitoid khối Ngọc Tụ còn thể hiện cả môi trường oxi hóa và khử (vừa đến mạnh) (Hình 7), điều này có thể do các đá granitoid khối này bị hiện tượng chlorit hóa, ít muscovit hóa, epidot hóa tác động.

\subsection{Tính chuyên hóa địa hóa của granitoid khối Ngọc Tu}

Đối với granitoid porphyr hạt lớn không có tính chuyên hóa địa hóa Mo $(K t t=1,36) \mathrm{Sn}, \mathrm{W}, \mathrm{Pb}$, Th có chuyên hóa. $U$ có chuyên hóa trung bình, còn Re thể hiện tính chuyên hóa rất cao (Bảng 1). Kết quả này đối với Mo ngược lại với các nghiên cứu trước đây, độ tin cậy của số liệu đảm bảo hơn. Tuy nhiên, $W$ chỉ mang tính tham khảo cao vì phân tích có sai số ngẫu nhiên lớn, nhưng kết quả phân tích của nguyên tố này vẫn phân định rất rõ ràng so với thực tế giữa đá gốc - đới biến đổi và đới khoáng hóa.

- Đối với granitoid hạt nhỏ nguyên tố $M o$ có tính chuyên hóa cao $(K t t=4,51)$ (Bảng 2), gần với ngưỡng chuyên hóa địa hóa cao. Kết quả này lần 
đầu tiên được xác định cùng quan hệ không gian và thời gian với kiểu đá granit porphyr hạt lớn và các mạch quặng thạch anh - molipdenit (các kết quả nghiên cứu trước đây chưa làm rõ điều này), độ tin cậy của bộ số liệu được kiểm tra đảm bảo để tính toán. Các nguyên tố khác như $W$ có chuyên

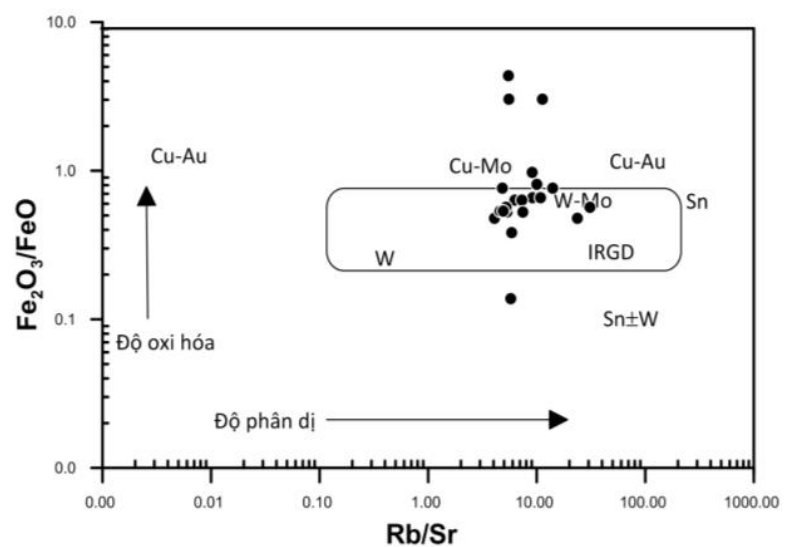

Hình 6. Biểu đồ tương quan giũa điều kiện oxy hóa, mức độ phân dị của granit khối Ngọc Tụ liên quan đến khoáng hóa (Blevin, 2004). hóa địa hóa cao, $U$ có chuyên hóa sinh khoáng (Ktt =6,07), $P b$ cũng có chuyên hóa địa hóa. Sn cũng có biểu hiện chuyên hóa địa hóa (Bảng 2) nhưng thấp hơn granit porphyr. Như vậy, $M o, U, W$ trong granit hạt nhỏ có tính chuyên hóa cao hơn nhiều so với granit porphyr hạt lớn.

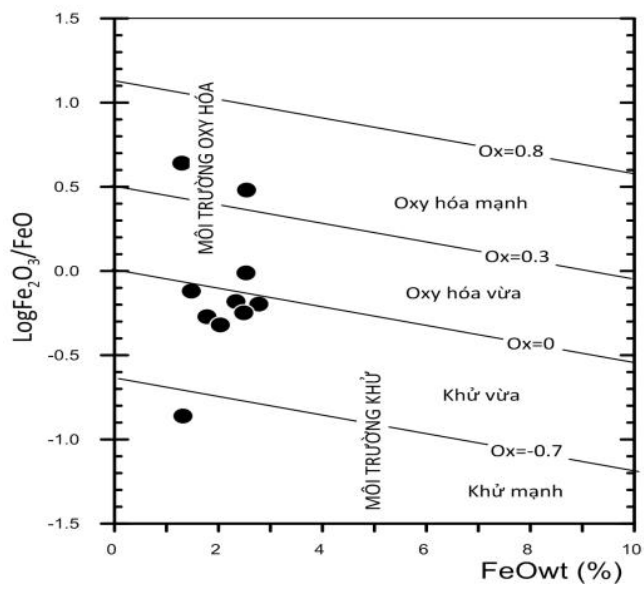

Hình 7. Biểu đồ phân loại điều kiện oxy hóa - khử của granit khối Ngọc Tụ (Blevin, 2004).

Bảng 1. Các tham số tính chuyên hóa địa hóa của granit porphyr khối Ngọc Tụ (n=12 mẫu).

\begin{tabular}{|c|c|c|c|c|c|c|c|c|}
\hline $\mathrm{NT}$ & $\begin{array}{c}\text { Min } \\
(\mathrm{ppm})\end{array}$ & $\begin{array}{c}\text { Max } \\
(\mathrm{ppm})\end{array}$ & $\begin{array}{c}\mathrm{TB} \\
(\mathrm{ppm})\end{array}$ & $(S)$ & $V(\%)$ & Ktt & $\begin{array}{c}\text { Clark A.A.Golovin, } \\
2000\end{array}$ & $\begin{array}{c}\text { Clark Vinogradop, } \\
1963\end{array}$ \\
\hline $\mathrm{Li}$ & 16,17 & 117,98 & 59,88 & 30,27 & 50,54 & 0,75 & 80 & \\
\hline $\mathrm{Be}$ & 3,14 & 9,81 & 5,07 & 1,84 & 36,22 & 1,45 & 3,5 & \\
\hline $\mathrm{Sc}$ & 3,70 & 5,40 & 4,48 & 0,49 & 11,01 & 0,64 & 7 & \\
\hline $\mathrm{V}$ & 10,49 & 23,36 & 16,45 & 3,28 & 19,92 & 0,23 & 70 & \\
\hline $\mathrm{Cu}$ & 1,85 & 30,26 & 6,44 & 7,75 & 120,39 & 0,26 & 25 & \\
\hline $\mathrm{Zn}$ & 21,02 & 37,38 & 30,46 & 4,91 & 16,12 & 0,53 & 58 & \\
\hline $\mathrm{Ga}$ & 14,10 & 18,40 & 16,09 & 0,95 & 5,93 & 0,85 & 19 & \\
\hline $\mathrm{Ge}$ & 2,68 & 3,91 & 3,01 & 0,30 & 9,86 & 2,01 & 1,5 & \\
\hline $\mathrm{Rb}$ & 350,57 & 446,43 & 392,17 & 29,64 & 7,56 & 1,96 & & 200 \\
\hline $\mathrm{Sr}$ & 38,01 & 76,04 & 58,39 & 11,48 & 19,67 & 0,22 & 270 & \\
\hline $\mathrm{Y}$ & 17,88 & 56,49 & 27,37 & 10,42 & 38,07 & 0,68 & 40 & \\
\hline $\mathrm{Nb}$ & 13,29 & 19,88 & 15,77 & 1,83 & 11,61 & 0,79 & 20 & 1 \\
\hline $\mathrm{Mo}$ & 0,45 & 9,41 & 2,04 & 2,69 & 131,63 & 1,36 & 1,5 & \\
\hline $\mathrm{Cd}$ & 0,03 & 0,09 & 0,05 & 0,01 & 30,72 & 0,27 & 0,17 & \\
\hline $\mathrm{Sn}$ & 5,15 & 10,81 & 7,30 & 1,54 & 21,06 & 2,43 & 3 & \\
\hline $\mathrm{Cs}$ & 11,62 & 32,78 & 20,33 & 6,33 & 31,13 & 4,07 & & \\
\hline $\mathrm{Ba}$ & 200,54 & 538,59 & 328,30 & 84,62 & 25,77 & 0,47 & 700 & \\
\hline $\mathrm{Hf}$ & 2,44 & 4,40 & 3,56 & 0,61 & 17,17 & 3,56 & & \\
\hline $\mathrm{Ta}$ & 1,63 & 3,61 & 2,55 & 0,66 & 25,83 & 1,02 & 2,5 & \\
\hline $\mathrm{W}$ & 0,90 & 44,50 & 6,57 & 10,63 & 161,69 & $\mathbf{3 , 2 9}$ & 2 & \\
\hline $\mathrm{Re}$ & 0,00 & 0,02 & 0,01 & 0,00 & 33,79 & 18,78 & 0,00067 & 20 \\
\hline $\mathrm{Pb}$ & 35,40 & 48,51 & 43,97 & 3,63 & 8,25 & $\mathbf{2 , 2 0}$ & 20 & \\
\hline $\mathrm{Th}$ & 27,93 & 52,35 & 38,35 & 6,97 & 18,18 & $\mathbf{2 , 1 3}$ & & \\
\hline $\mathrm{U}$ & 4,44 & 32,52 & 12,35 & 7,79 & 63,02 & $\mathbf{3 , 5 3}$ & & \\
\hline
\end{tabular}


Bảng 2. Các tham số tính chuyên hóa địa hóa của granitoid hạt nhỏ khối Ngọc Tụ ( $n=6$ mẫu).

\begin{tabular}{|c|c|c|c|c|c|c|c|c|}
\hline NT & $\begin{array}{c}\text { Min } \\
(\mathrm{ppm})\end{array}$ & $\begin{array}{c}\text { Max } \\
(\mathrm{ppm})\end{array}$ & $\mathrm{TB}(\mathrm{ppm})$ & $(S)$ & $V(\%)$ & Ktt & $\begin{array}{c}\text { Clark A.A.Golovin, } \\
2000\end{array}$ & $\begin{array}{c}\text { Clark Vinogradop, } \\
1963\end{array}$ \\
\hline $\mathrm{Li}$ & 22,09 & 35,03 & 27,87 & 5,34 & 19,16 & 0,35 & 80 & \\
\hline $\mathrm{Be}$ & 3,03 & 13,32 & 7,42 & 4,40 & 59,35 & 2,12 & 3,5 & \\
\hline $\mathrm{Cu}$ & 5,98 & 28,10 & 20,15 & 10,28 & 50,99 & 0,81 & 25 & \\
\hline $\mathrm{Zn}$ & 8,53 & 15,92 & 12,76 & 3,08 & 24,14 & 0,22 & 58 & \\
\hline $\mathrm{Ga}$ & 13,64 & 19,81 & 15,66 & 2,82 & 17,99 & 0,82 & 19 & \\
\hline $\mathrm{Ge}$ & 2,10 & 2,37 & 2,21 & 0,12 & 5,40 & 1,48 & 1,5 & \\
\hline $\mathrm{Rb}$ & 399,28 & 442,14 & 418,95 & 17,62 & 4,21 & 2,09 & & 200 \\
\hline $\mathrm{Sr}$ & 16,51 & 38,45 & 28,08 & 9,20 & 32,77 & 0,10 & 270 & \\
\hline $\mathrm{Y}$ & 8,67 & 18,51 & 14,82 & 4,48 & 30,23 & 0,37 & 40 & \\
\hline $\mathrm{Zr}$ & 26,22 & 53,33 & 36,46 & 11,75 & 32,22 & 0,18 & & 200 \\
\hline $\mathrm{Nb}$ & 8,75 & 15,72 & 12,42 & 3,11 & 25,00 & 0,62 & 20 & 1,5 \\
\hline $\mathrm{Mo}$ & 2,84 & 11,10 & 6,76 & 4,35 & 64,34 & 4,51 & 0,17 & \\
\hline $\mathrm{Cd}$ & 0,03 & 0,03 & 0,03 & 0,00 & 11,63 & 0,17 & 3 & \\
\hline $\mathrm{Sn}$ & 4,46 & 8,17 & 5,89 & 1,69 & 28,67 & 1,96 & & \\
\hline $\mathrm{Ba}$ & 29,26 & 68,83 & 56,33 & 18,23 & 32,36 & 0,08 & 700 & \\
\hline $\mathrm{Hf}$ & 1,28 & 1,71 & 1,44 & 0,19 & 13,43 & 1,44 & & \\
\hline $\mathrm{Ta}$ & 1,27 & 3,98 & 2,32 & 1,19 & 51,43 & 0,93 & 2,5 & \\
\hline $\mathrm{W}$ & 2,76 & 15,78 & 9,27 & 5,69 & 61,43 & 4,63 & 2 & \\
\hline $\mathrm{Re}$ & 0,00 & 0,01 & 0,01 & 0,00 & 40,42 & 13,22 & 0,00067 & \\
\hline $\mathrm{Pb}$ & 37,42 & 59,31 & 49,22 & 9,98 & 20,28 & 2,46 & 20 & \\
\hline $\mathrm{Th}$ & 9,35 & 13,51 & 11,38 & 1,76 & 15,43 & 0,63 & & \\
\hline $\mathrm{U}$ & 10,79 & 29,36 & 21,23 & 8,42 & 39,65 & 6,07 & & \\
\hline & & & & & & & & \\
\hline
\end{tabular}

\subsection{Thảo luận}

Về đặc điểm thạch học có một số khác biệt với kết quả nghiên cứu trước đây: granit dạng porphyr ở đây là chủ yếu. Còn granit hạt nhỏ ít gặp. Hiện tượng biến đổi đá gốc phổ biến gồm: chlorit hóa, anbit hóa, epidot hóa, bezerit hóa và greisen hóa. Các đặc điểm này sẽ làm cơ sở vững chắc cho việc luận giải các tham số địa hóa, hành vi địa hóa các nguyên tố khi xác định tính chuyên hóa địa hóa.

Kết quả về thành phần bao thể nguyên sinh đặc trưng cho môi trường magma granitoid khối Ngọc Tụ có tính oxy hóa - khử. Như vậy, trong quá trình tiến hóa magma khối Ngọc Tụ từ dạng đá granit porphyr với granit hạt nhỏ tăng thành phần và nồng độ chất lưu trong bao thể nguyên sinh, giàu $\mathrm{CO}_{2}, \mathrm{H}_{2} \mathrm{O}$ thể hiện rõ tính oxy hóa (Yves Moussallam và nnk., 2016; Bakker và nnk., 2000) của đá granit khu vực nghiên cứu, trong đó các mẫu chưa phát hiện được bất kỳ loại chất lưu. Ngoài ra, sự xuất hiện của các bao thể giàu $\mathrm{F}$ đặc trưng cho thành phần chất bốc. Granitoid hạt nhỏ sinh sau biểu hiện tăng thành phần $\mathrm{H}_{2} \mathrm{O}$ trong bao thể nguyên sinh.

Ngoài bao thể nguyên sinh, còn gặp các dạng bao thể hỗn hợp và bao thể thứ sinh. Đặc điểm phân bố dạng dải, theo các khe nứt hay các bao thể nguyên sinh bị nứt tách tạo nên dạng bọt gồm các bao thể nhỏ cho thấy khu vực này bị biến dạng. Hiện tượng này có lẽ cũng phù hợp với quá trình khối magma granit xuyên cắt các thành tạo biến chất cổ trong khu vực làm thay đổi áp suất riêng của hơi nước thuộc phạm vi tiếp xúc, hình thành các khe nứt trong nội khối cùng việc tái phân bố lại thành phần vật chất, trong đó có Mo.

Hàm lượng trung bình số học của $M o$ trong khối Ngọc Tụ rất cao (135,94ppm). Trong khi đó, hàm lượng trung bình trọng số đặc trưng cho granitoid khối Ngọc Tụ 1,52 ppm (giá trị này thường thấp hơn giá trị hàm lượng nền địa phương). Sự chênh lệch rất lớn giữa hàm lượng trung bình số học và trung bình trọng số này phản ánh sự rất khác biệt giữa dị thường âm tối thiểu $(0,45 \mathrm{ppm})$ và hàm lượng lớn nhất - max (3.134,34 ppm) của tập mẫu (18 mẫu) (Bảng 3, 
Hình 8). Đồng thời, giá trị lớn nhất này và một số điểm có hàm lượng cao $(189,3$ ppm) thuộc mẫu đột biến (max outlier), rất có ý nghĩa cho tìm kiếm. ở đây, hai điểm này (chúng cạnh nhau) đã tìm thấy quặng dạng mạch thạch anh - molipden cùng các sulfua của $C u, \ldots$ Đi cùng với hai mẫu đột biến $M o$ này cũng là hai điểm có sự đột biến về hàm lượng $C u$ và $W$. Đồng thời, tại đới biến đổi gần mạch quặng thạch anh - molybdenit đã gặp khoáng vật uraninit nhưng hàm lượng $U$ không cao $(<10 \mathrm{ppm})$.

- Giá trị dị thường tối thiếu của $M o$ là 12,33 ppm. Trên ngưỡng hàm lượng này gặp một dị thường đạt 14,27 ppm điểm này thuộc đới bezerit hóa, chứa vài hạt molybdenit thuộc khu vực chứa các mạch nhỏ thạch anh - molybdenit (hạt lớn, dạng hoa hồng) và nhiều vi mạch thạch anh trên diện tích kéo dài vài trăm mét.

Bảng 3. Các tham số địa hóa của Mo và các nguyên tố liên quan của granitoid khối Ngọc Tụ.

\begin{tabular}{|c|c|c|c|c|c|c|c|c|}
\hline Tham số/nguyên tố & Đơn vị & $\mathrm{W}$ & $\mathrm{Cu}$ & Sn & Mo & $\mathrm{Pb}$ & $\mathrm{Zn}$ & $\mathrm{U}$ \\
\hline Số mẫu & mẫu & 18 & 18 & 18 & 18 & 18 & 18 & 18 \\
\hline \% giá trị đột biến & $\%$ & 11,54 & 7,69 & 7,69 & 7,69 & 11,54 & 3,85 & 0,00 \\
\hline Độ lệch chuẩn & & 296,86 & 114,42 & 6,90 & 625,78 & 27,94 & 13,52 & 296,86 \\
\hline Hệ số biến phân $(V)$ & $\%$ & 333,53 & 277,11 & 79,16 & 460,32 & 49,84 & 51,42 & 62,38 \\
\hline Min & \multirow{6}{*}{ ppm } & 0,90 & 1,85 & 1,41 & 0,45 & 35,40 & 7,13 & 1,38 \\
\hline Max & & 1445,90 & 501,04 & 35,04 & 3134,31 & 169,78 & 72,13 & 32,52 \\
\hline Median & & 5,63 & 5,37 & 6,90 & 1,52 & 46,22 & 27,44 & 10,79 \\
\hline Average & & 89,01 & 41,29 & 8,71 & 135,94 & 56,06 & 26,30 & 13,08 \\
\hline Di thường dương tối thiểu & & 21,00 & 40,20 & 12,81 & 12,33 & 71,35 & 60,04 & 32,52 \\
\hline Dị thường ấm tối thiểu & & 0,90 & 1,85 & 1,47 & 0,45 & 35,40 & 7,13 & 1,38 \\
\hline Số giá trị đột biến & & 2 & 2 & 0 & 2 & 0 & 0 & 0 \\
\hline $\begin{array}{l}\text { Số giá trị trên ngưỡng dị thường } \\
\text { dương tối thiểu }\end{array}$ & & 3 & 2 & 1 & 2 & 3 & 1 & 0 \\
\hline $\begin{array}{l}\text { Số giá trị dưới ngưỡng dị thường } \\
\text { âm tối thiểu }\end{array}$ & & 0 & 0 & 1 & 0 & 0 & 0 & 0 \\
\hline Giá trị đột biến lớn nhất & \multirow{2}{*}{ ppm } & 1445,90 & 501,04 & 35,04 & 3134,31 & 169,78 & 72,13 & \\
\hline Giá trị đột biến nhỏ nhất & & & & 1,41 & & & & \\
\hline Độ tương phản của dị thường & & 68,85 & 12,46 & 2,73 & 254,21 & 2,38 & 1,20 & \\
\hline
\end{tabular}

Ghi chú: Dị thường dương tối thiểu là giá trị biểu thị cho khả năng liên quan đến quá trình tích tụ một nguyên tố nào đó, có thể tạo khoáng.

- Dị thường âm tối thiểu là giá trị biểu thị cho khả năng liên quan đến quá trình di chuyển một nguyên tố nào đó một cách bất thường, có thể dẫn tới quá trình tạo quặng ở vị trí khác thuận lợi về các điều kiện địa chất.

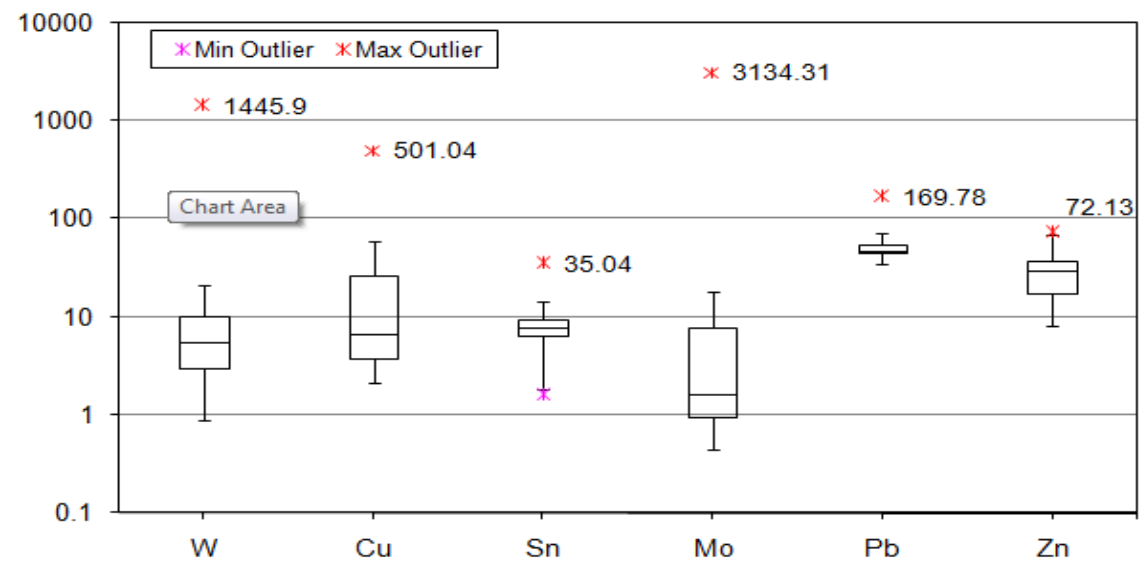

Hình 8. Biểu đồ xác định các tham số địa hóa (dị thường tối thiểu, trung bình trọng số, giá trị đột biến,...) của granitoid khối Ngọc Tụ (Chú ý: giá trị max outlier trên biểu đồ là giá trị lón nhất, có thể tương đương với giá trị đột biến). 
- Hệ số biến phân hàm lượng Mo rất cao $(V=$ $460,32 \%$ ) và độ tương phản dị thường của Mo rất lớn $(254,21)$. Điều này có thể sự linh động của Mo từ đá gốc ra môi trường có điều kiện địa chất thuận lợi sẽ tích tụ và tạo khoáng. $W, C u$ cũng có hệ số biến phân cao, nhưng độ tương phản của dị thường thấp hơn $M o$ rất nhiều (Bảng 3 ).

Đặc điểm phân bố của $M o$ (Hình 9,10 ) trong granit hạt nhỏ và granit porphyr hạt lớn rất khác biệt. Trong khi đó tại đới đá granitoid porphyr chứa các mạch thạch anh - molybdenit xuyên cắt.

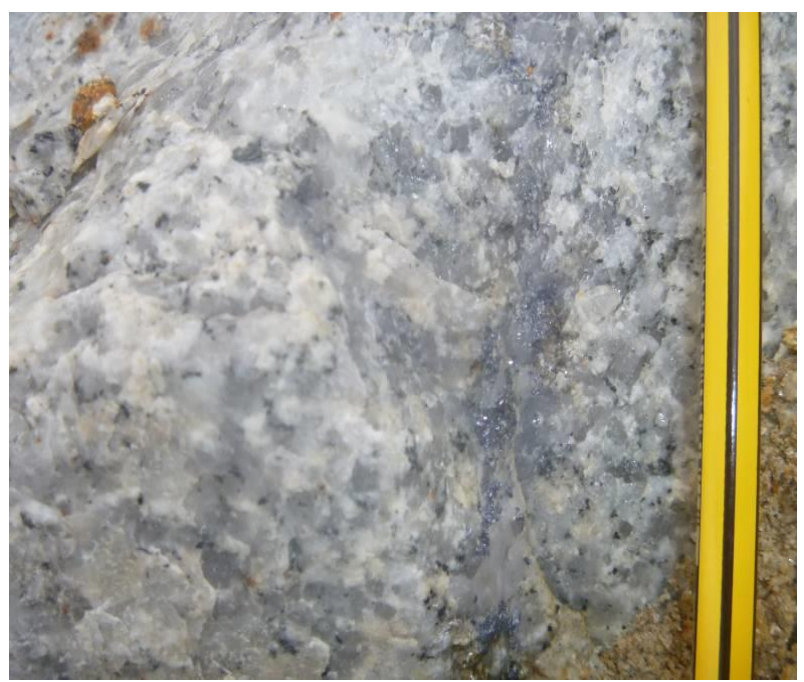

Hình 9. Molybdenit hạt nhỏ xâm tán trong vi khe nút của đá granitoid bi biến đổi sericit hóa, ít muscovit hóa, albit hóa yếu tại điểm khoáng hóa molybden Ngọc Tụ (Nguyễn Văn Niệm, Đỗ Đức Nguyên, 2014; 2018).

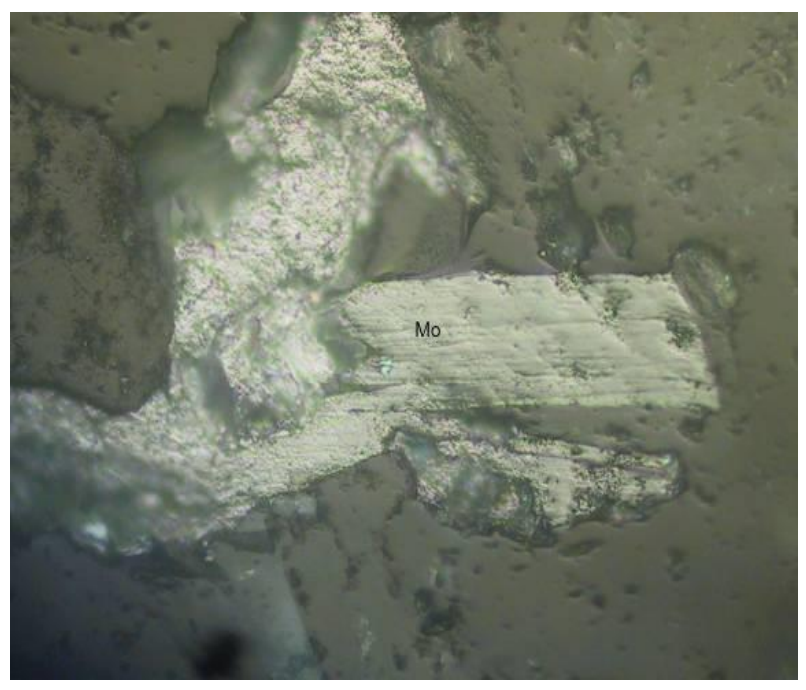

Hình 10. Molybdenit xâm tán trong nền đá biến đổi tại điểm khoáng hóa molipden Ngọc Tu, Đăk Tô, Kon Tum. Nicol ( - ), 100 lần.
Về đặc điểm tương quan giữa Mo và các nguyên tố: Mo là nguyên tố không có quan hệ (tương quan thuận) với bất kỳ nguyên tố nào trong granitoid khối Ngọc Tụ. Đồng thời, nó có tương quan nghịch với nhóm nguyên tố đất hiếm (REE), Sn, Zn, Ta, Hf, Th.

\section{Kết luận}

Đặc tính granitoid khối Ngọc Tụ biểu hiện cả hai môi trường oxy hóa - khử, đặc tính này thuận lợi chokhả năng sinh khoáng $\mathrm{Mo}, \mathrm{Cu}$ - Mo và $\mathrm{W}$. Granitoid khối Ngọc Tụ có tính chuyên hóa Re, Mo, W, U cao, không có tính chuyên hóa sinh khoáng của Sn.Trên cở sở tính chuyên hóa địa hóa khá phù hợp với tích tụ như điểm khoáng hóa Mo, W.

\section{Đóng góp của các tác giả}

- Đỗ Đức Nguyên, Nguyễn Văn Niệm: lên ý tưởng; Đinh Công Tiến, Hoàng Thị Thoa, Hoàng Thị Thùy Linh, Bùi Trọng Tấn; Đỗ Đức Nguyên, Phạm Hùng Thanh, Dương Công Hiếu: thu thập dữ liệu; phân tích dữ liệu; Đỗ Đức Nguyên, Nguyễn Văn Niệm: viết bản thảo gốc; Đỗ Đức Nguyên, Bùi Trọng Tấn: chỉnh sửa bản thảo.

\section{Tài liệu tham khảo}

Bakker, R. J., (2000). Fluid inclusions as metamorphic process indicators in the Southern Aravalli Mountain Belt (India). Contributions to Mineralogy and Petrology 139(2), 163-179.

Blevin P. L. (2004). Metallogeny of granite rocks. The Ishihara Symposium: Granites and associated metallogenesis. Geoscience Australia. www.ga.gove.au.

Dương Đức Kiêm. (2006). Nghiên cưu sinh khoáng và dụ báo triển vọng khoáng sản đới cấu trúc kiến tạo Pô Cô. Lưu trữ Địa chất. Hà Nô̂i

Moussallam, Y., Edmonds, M., Scaillet, B., Peters, N., Gennaro, E., Sides, I., \& Oppenheimer, C. (2016). The impact of degassing on the oxidation state of basaltic magmas: a case study of Kilauea volcano. Earth and Planetary Science Letters, 450, 317 - 325.

Nguyễn Quang Lộc. (1998). Báo cáo thuyết minh, Bản đồ địa chất và khoáng sản nhóm tờ Đắk Tô 
tỷ lệ 1:50.000. Lưu trũ Địa chất. Hà Nội.

Nguyễn Văn Niệm, Đỗ Đức Nguyên. (2014). Nghiên cúu đặc điểm địa hóa của molipden trong thành tạo granitoid khối Ngọc Tụ (phức hệ Bà Nà) làm cơ sở dự báo tiềm năng khoáng sản molipden. Viện Khoa học Địa chat và Khoáng sản. Hà Nội.

Nguyễn Văn Niệm, Đỗ Đức Nguyên. (2018). Nghiên cứu chuyên hóa địa hóa molipden các thành tạo granitoid kiểu Bà Nà và tiềm năng sinh khoáng Mo của chúng. Viện Khoa học Địa chat và Khoáng sản. Hà Nội.

Trần Hoàng Vũ. (2015). Tuổi đồng vị U - Pb trong zircon của granit khối Ngọc Tụ, huyện Đăk Tô, tỉnh Kon Tum. Hội nghị Khoa học kỷ niệm 75 năm thành lập Ngành địa chất. Tong cục Địa chat và Khoáng sản. Hà Nội.

Trần Tınh, Nguyễn Văn Trang. (1994). Báo cáo kết quả đo vẽ địa chất và tìm kiếm khoáng sản nhóm tò̀ Kon Tum - Buôn Mê Thuột tỷ lệ 1/200.000. Lưu trũ̃ Địa chat. Ha Nội. 